\title{
Breaking the Barrier in Endoscopy
}

\author{
Partha Pal ${ }^{1}$ Mohan Ramchandani ${ }^{1}$ Inavolu Pradev ${ }^{1}$ Aniruddha Pratap Singh ${ }^{1}$ \\ Duvvuru Nageshwar Reddy ${ }^{1}$
}

1 Department of Gastroenterology, Asian Institute of

Gastroenterology, Hyderabad, Telangana, India

Address for correspondence Mohan Ramchandani, MD, DM, Department of Interventional Endoscopy, AIG Hospitals, Asian Institute of Gastroenterology, No 136, Plot No 2/3/4/5 Survey, 1,

J Digest Endosc 2021;12:235-241. Mindspace Rd, Gachibowli, Hyderabad, Telangana 500032, India (e-mail: ramchandanimohan@gmail.com).
Abstract
Keywords
- deep enteroscopy
- motorized spiral enteroscopy
- cholangioscopy
- pancreatoscopy
- third-space endoscopy
- peroral endoscopic myotomy

In this narrative review, invited by the Editors of the Journal of Digestive Endoscopy, we summarize recent advances in the field of gastrointestinal endoscopy with regard to reaching the earlier inaccessible areas in the gut by newer methods and technology. This article primarily discusses recent advances in the past few years in the following headings: (1) reaching redundant small bowel via enteroscopy (primarily motorized spiral enteroscopy), (2) reaching the thin pancreaticobiliary ducts via cholangioscopy and pancreatoscopy, (3) going out of the gut wall: third-space endoscopy (primarily peroral endoscopic myotomy: POEM). A thorough literature review was performed on each topic describing how the advances were evolving.

\section{Introduction}

Innovations in the field of gastrointestinal (GI) endoscopy over the last two decades have made it possible to reach the earlier inaccessible areas in the GI tract. Methods of deep small bowel endoscopy by balloon-assisted enteroscopy were far from ideal due to sub-optimal pan-enteroscopy rates and prolonged procedure time. Difficult biliary/pancreatic stones and indeterminate strictures were often subjected to surgical therapy. GI diseases such as achalasia cardia and refractory gastroparesis often required surgical myotomy until submucosal space was recognized as a potential operative field as thirdspace endoscopy evolved. All these potential barriers in interventional endoscopy have been circumvented by newer technologies such as motorized spiral enteroscopy, cholangiopancreatoscopy, and third-space endoscopy. These innovations are propelling the field of advanced GI endoscopy forward. We describe our experience with regard to the technological evolutions and landmarks we observed over the last two decades.

\section{Venturing Deep into Small Bowel}

\section{Evolution of Small Bowel Enteroscopy}

The first breakthrough in deep enteroscopy began with the invention of the double-balloon enteroscope (DBE) (Fujifilm, Tokyo, Japan) way back in 2001 in Japan by Hironori Yamamoto. ${ }^{1}$ This was followed by the introduction of single-balloon enteroscopy (SBE) (Olympus Medical Systems Corp, Tokyo) in $2007 .^{2}$ Compared with DBE, SBE has only one balloon located at the tip of the over-tube and uses the hooked tip of the endoscope to fix the intestine. SBE is noninferior to DBE with regard to the depth of insertion, diagnostic yield, and rate of complications with shorter preparation and investigation time although panenteroscopy rates are better with DBE. ${ }^{3}$ Principles of balloon-
DOI https://doi.org/ 10.1055/s-0041-1741386. ISSN 0976-5042. (c) 2022. Society of Gastrointestinal Endoscopy of India. All rights reserved.

This is an open access article published by Thieme under the terms of the Creative Commons Attribution-NonDerivative-NonCommercial-License, permitting copying and reproduction so long as the original work is given appropriate credit. Contents may not be used for commercial purposes, or adapted, remixed, transformed or built upon. (https://creativecommons.org/ licenses/by-nc-nd/4.0/)

Thieme Medical and Scientific Publishers Pvt. Ltd., A-12, 2nd Floor, Sector 2, Noida-201301 UP, India 


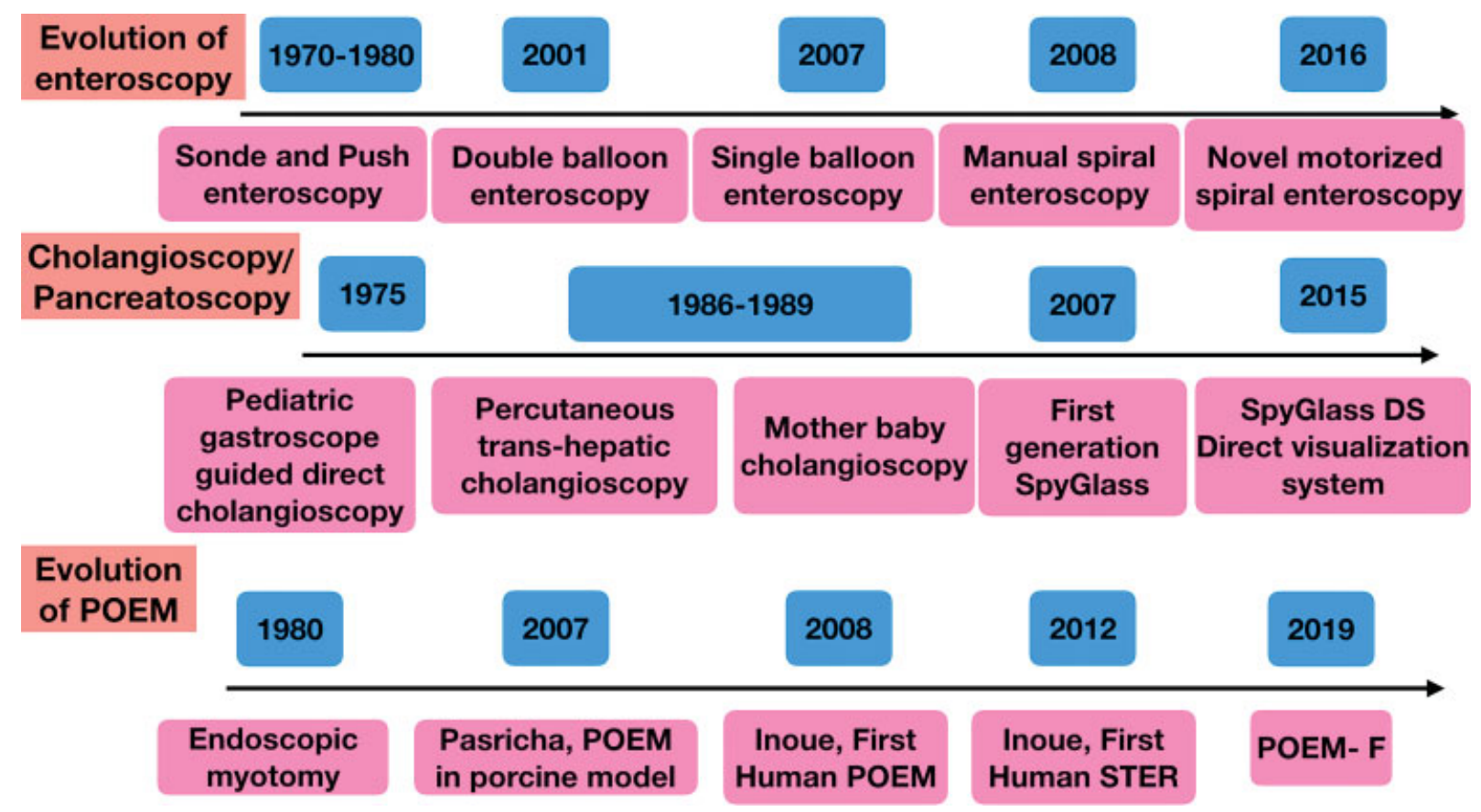

Fig. 1 "Breaking the barrier in endoscopy": evolution of deep enteroscopy, chonagiopancreatoscopy, and third-space endoscopy (peroral endoscopic myotomy: POEM); POEM-F: peroral endoscopic myotomy with fundoplication.

assisted enteroscopy (BAE) depend upon the serial "push and pull maneuver" to pleat the small intestine. A large study from India including 106 patients showed diagnostic yields of $55 \%, 60 \%$, and $65 \%$ for chronic diarrhea, obscure GI bleed, and chronic abdominal pain, respectively, with a $25 \%$ panenteroscopy rate. Therapeutic interventions were performed in $21 \%$ via SBE, which included argon plasma coagulation (APC), polypectomy, stricture dilatation, foreign body extraction, and hemoclips for jejunal Dieulafoy's lesion (-Fig. 1) ${ }^{4}$

After SBE, manual spiral enteroscopy (SE) (Spirus Medical, Stoughton, Mass, USA) was introduced in $2008 .{ }^{5}$ SE depends on the principle of "rotation" rather than "push and pull." The spiral overtube was $118 \mathrm{~cm}$ long, which was compatible with standard single and double-balloon enteroscope $(200 \mathrm{~cm})$. This left only 90 to $95 \mathrm{~cm}$ of effective length and only 30 to $35 \mathrm{~cm}$ of functional scope beyond the ligament of Treitz to perform small bowel pleating, making it difficult to perform pan-enteroscopy even by the most experienced endoscopist. Also, the requirement for manual spiral rotation caused significant wear and tear on the endoscopist. SE has a similar diagnostic and therapeutic yield, similar depth of insertion but importantly shorter procedure time compared with BAE based on a systematic review and meta-analysis. ${ }^{6}$ In a series of 11 cases of SE reported from India, the mean procedure time was 27.8 minutes (range: 20-32 minutes) (considerably lower than BAE) with an average depth of insertion of $249 \mathrm{~cm}$ $(120-400 \mathrm{~cm})$. No major complications were noted. ${ }^{7}$

\section{Novel Motorized Spiral Enteroscopy}

NMSE has addressed prior technical challenges in SE. It uses a longer enteroscope (working length $168 \mathrm{~cm}$ ) with a short spiral over-tube $(24 \mathrm{~cm})$, which increases the likelihood of pan-enteroscopy. An integrated water jet system and a larger working channel diameter $(3.2 \mathrm{~mm})$ allow for better therapeutic endoscopy. ${ }^{8}$ A user-controlled spiral motor unit allows for a single operator to perform the procedure in an even faster and simplified manner. In a prospective clinical feasibility study of 140 procedures performed in two centers; the technical success, diagnostic yield, median depth of insertion, median insertion time, anterograde pan-enteroscopy rate, and major adverse events were $97 \%, 74.2 \%, 450 \mathrm{~cm}, 25$ minutes, $10.6 \%$ and $1.5 \%$ respectively. ${ }^{9}$ Total enteroscopy rate was reported to be $70 \%$ (in $53.4 \%$ pan-enteroscopy was achieved by bidirectional approach and in $16.6 \%$ cases by only antegrade approach). ${ }^{10}$ Compared with western studies, the first realworld data from India on diagnostic yield and therapeutic impact of NMSE showed pan-enteroscopy rate was $60.6 \%$ of which $31.1 \%$ was noted in antegrade and $29.5 \%$ in bidirectional enteroscopy. Technical success and diagnostic yields were $93.4 \%$ and $65.5 \%$, respectively. Also, $23 \%$ of patients underwent therapeutic spiral enteroscopy. No serious adverse events were reported. The major advantages of NMSE are shorter procedure time, single-operator use, higher pan-enteroscopy rates, and better provision of therapeutic small bowel endoscopy. ${ }^{8}$ NMSE-guided removal of the impacted video capsule endoscope in distal ileum in a case of multifocal stricturizing Crohn's disease after balloon dilation of strictures has been reported. ${ }^{11}$ This has the potential to revolutionize the management of small bowel disorders (-Fig. 2).

\section{Exploring the Ducts}

Evolution of Cholangioscopy and Pancreatoscopy Endoscopic retrograde cholangiopancreatography (ERCP) is the main diagnostic and therapeutic modality for biliary 


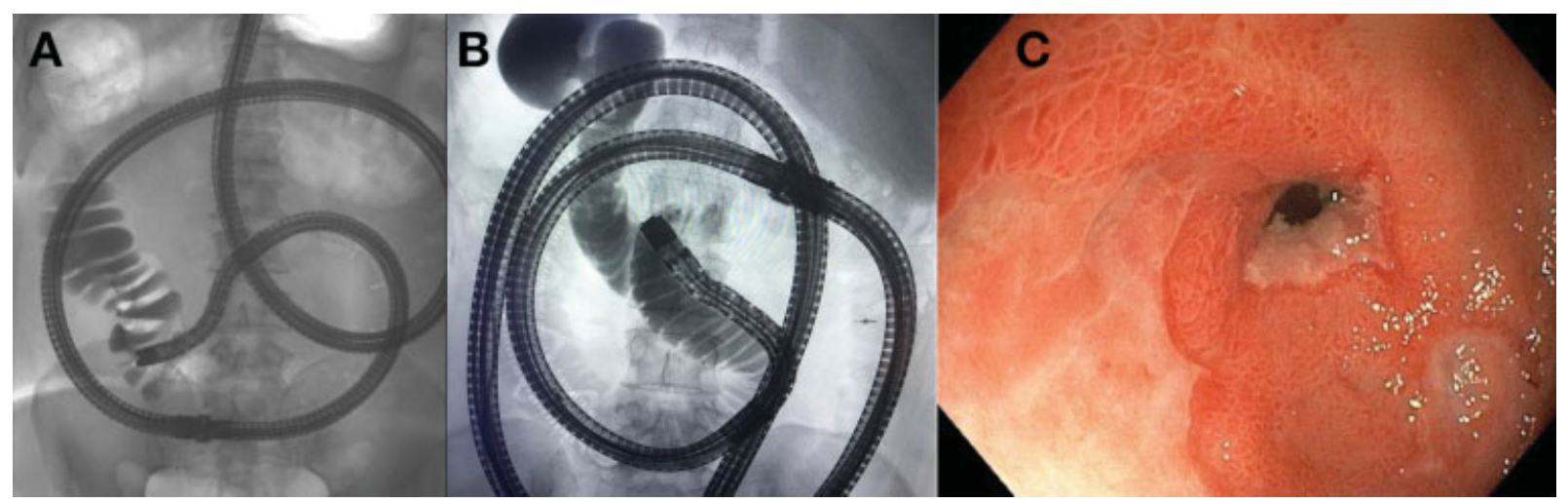

Fig. 2 Novel motorized spiral enteroscopy (NMSE). (A) Antegrade pan-enteroscopy with NMSE: contrast injection showing opacification of the cecum, (B) Retrograde pan-enteroscopy with NMSE: contrast injection showing opacification of duodenal bulb, (C) Circumferential non-passable ulcerated stricture in mid ileum seen via antegrade route.

tract disorders that use fluoroscopy. However, ERCP has limitations in various biliary tract disorders such as stricture, tumor, cyst, and filling defects that may warrant direct visualization of the biliary tract. Differentiating benign and malignant biliary disease with brush cytology and biliary biopsy is suboptimal. Also, 5 to $10 \%$ of biliary stones may not be amenable to ERCP, endoscopic papillary balloon dilation (EPBD), and even mechanical lithotripsy. ${ }^{12}$ To overcome the limitations, per-oral cholangioscopy was first performed in 1975. Since then, there are serial advancements in methods, accessories, and techniques the last few decades ( - Fig. 1).

Cholangioscopy can be done peroperatively, per-orally, or through percutaneous trans-hepatic route. The percutaneous route requires a large diameter, trans-hepatic tract that requires time to mature and is associated with risk of bile leak, bleeding, and tumor seeding along the tract. Hence, per-oral cholangioscopy is most popular that can be done directly via ultra-thin caliber endoscope or indirectly via the insertion of a cholangioscope through the accessory channel of the duodenoscope. Direct peroral cholangioscopy (DPOC) requires prior sphincterotomy/ sphincteroplasty for the advancement of ultra-thin caliber endoscope. It is technically challenging due to the looping of the endoscope in the stomach and the lack of stability while advancing the endoscope through the biliary system. Hybrid balloon catheter anchoring device and double bending cholangioscope are the few of those technical modifications to overcome the challenges. Moreover, the risk of air embolism is present that may occur due to excessive gas pressure in thin caliber biliary system. ${ }^{12}$ Advantages of DPOC include higher image resolution and higher caliber of the accessory channel. Image-enhanced endoscopy (IEE) during DSOC can help differentiate benign from a malignant tumor and define tumor margin by evaluating surface and micro-vasculature. Indirect cholangioscopy using mother duodenoscope and baby cholangioscope requires two operators, has highly fragile instruments, and is associated with high cost. It has fallen out of favor due to the above factors along with poor image resolution, provision of only two way deflection of cholangioscope tip, longer set up, and procedure time. ${ }^{12}$

\section{Single Operator Peroral Cholangioscopy}

Single operator system initially consisting of the directable plastic sheath and a reusable fiber-optical light and image guide (Legacy SpyGlass, Boston Scientific, Marlborough, Massachusetts) have addressed some of the limitations of a dual operator system. It can be advanced into the biliary system with or without wire guidance by a single operator controlling the mother duodenoscope and $3.3 \mathrm{~mm}$ diameter baby cholangioscope. Cholangioscope has a four-way tip deflection and two channels (for irrigation and suction). This allows for higher maneuverability and passage of accessories such as biopsy forceps, endomicroscopy probe, snare, or basket allowing therapeutic procedures such as laser or electrohydraulic lithotripsy (EHL). ${ }^{12}$ A prospective study from India has demonstrated that the visual impression of the SpyGlass is accurate in $89 \%$ of cases to differentiate benign from the malignant lesion, whereas targeted SpyBite biopsies are accurate in $82 \%$, which is far higher than brushing cytology/blind biliary biopsy. Irregularly dilated tortuous vessels, papillary/villous projections, and nodularity/mass were the characteristics of a malignant lesion. A homogenous granular mucosa devoid of any mass and smooth surface without neovascularization were criteria for benign lesions. ${ }^{13}$ In a series of five cases from India showed that SOPOC with intraductal ultrasound (IDUS) can be helpful in the evaluation and management of portal biliopathy when the cause of obstruction is not well defined by identifying pericholedochal collaterals, intraductal varices or ischemic stricture. ${ }^{14}$

\section{Digital Single Operator Cholangioscopy}

Cholangioscopy was revolutionized using DSOC (SpyGlass DS, Boston Scientific) with disposable cholangioscope that captures images digitally. DSOC is superior to fiberoptic single operator cholangioscopy (FSOC) with regard to image quality, visualization and maneuverability, especially for targeting left intraductal lesion in a randomized novel cholangioscopy bench model study (-Fig. 3). ${ }^{15}$

The advantages of DSOC include:

(1) Feasibility of radiation-free ERCP

(2) Direct visualization of the biliary system 


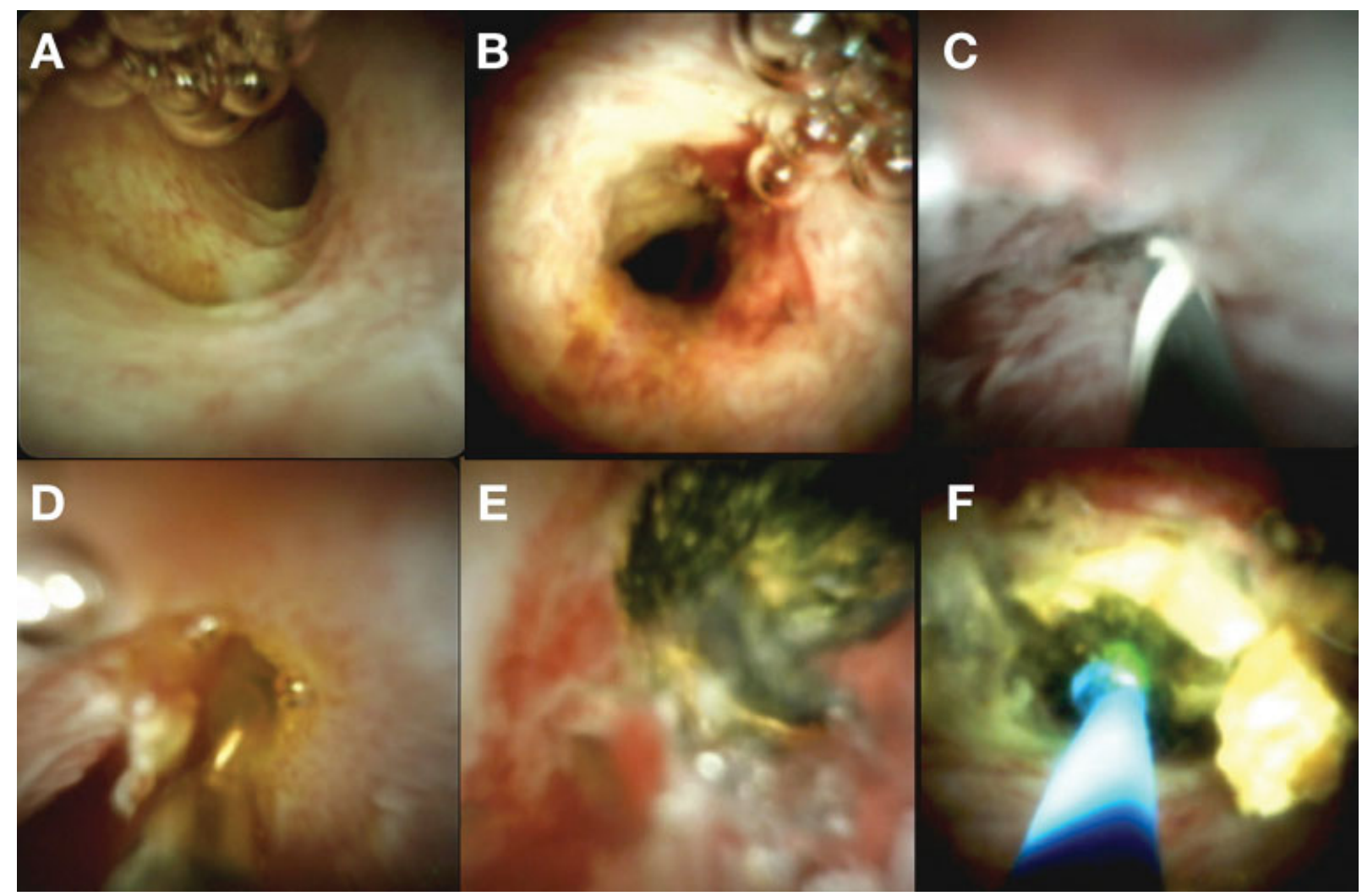

Fig. 3 SpyGlass DS single operator cholangioscopy. (A) Benign stricture on cholangioscopy showing smooth surface without neovascularization. (B) IgG4 related cholangiopathy-related stricture on cholangioscopy. (C) Nodularity and irregular vessels in a tight malignant stricture negotiated with catheter. (D) Spybite biopsy being taken during cholangioscopy. (E) Impacted stone is seen on cholangioscopy. (F) Stone fragmentation by laser lithotripsy.

(3) Tissue acquisition

(4) Cholangioscopy-directed therapy

Radiation-free ERCP could be valuable particularly in pregnant females as shown in a recent multicenter study, in which DSOC helped in avoiding fluoroscopy in $50 \%$ of cases. ${ }^{16}$

A multi-center randomized controlled study has shown higher sensitivity (68.2\%) and accuracy (76.7\%) of DSOCguided tissue sampling compared with conventional ERCPguided brush cytology (21.4\% sensitivity, 59.3\% accuracy) with similar adverse event profile in indeterminate biliary strictures. ${ }^{17}$ Importantly, the visual impression on DSOC had a sensitivity of $95.5 \%$ with an overall accuracy of $87.1 \% .{ }^{17}$ This has important clinical implications as malignant-looking operable lesions on cholangioscopy can be offered surgery even if tissue sampling is inconclusive. An expert consensus statement has enumerated indications of peroral cholangiography: (1) targeted biopsy in indeterminate biliary strictures, (2) cholangioscopy-guided lithotripsy when standard techniques fail. ${ }^{18}$ This has been substantiated by two recent large multi-center studies. The first one on cholangioscopyguided tissue acquisition showed that cholangioscopic visual impression and tissue acquisition had an overall accuracy of $77.2 \%$ and $86.5 \%$, respectively. ${ }^{19}$ The second one showed that cholangioscopy-guided lithotripsy was effective in stone clearance in a single session in $80 \%$ of cases (among whom
$80 \%$ had earlier failed ERCP), especially for less than $3 \mathrm{~cm}$ stones. ${ }^{20}$ Latest consensus guidelines state that cholangioscopy-guided visualization and -guided biopsy during initial ERCP may reduce the need for multiple procedures in indeterminate strictures (except for distal biliary strictures) although it is associated with a higher risk of cholangitis than standard ERCP necessitating prophylactic antibiotics and adequate biliary drainage. $^{21}$

\section{Single Operator Pancreatoscopy}

Single operator pancreatoscopy (SOP) has been used for the evaluation of indeterminate pancreatic duct strictures and intraductal papillary mucinous neoplasm (IPMN). Therapeutic interventions such as intraductal lithotripsy and even intraductal necrosectomy in walled-off necrosis (WON) have been described. ${ }^{22}$ In a large single-center study $(n=41)$, SOP helped in directed biopsy and classification in suspected IPMN and impacted clinical management in $76 \%$ by providing additional information or tissue diagnosis. Post ERCP pancreatitis occurred in $17 \%{ }^{23}$

SOP-guided electrohydraulic lithotripsy (EHL) and laser lithotripsy (LL) can achieve complete ductal clearance in 89.9\% and a single session was required in $73.5 \%$ according to a large $(n=109)$ retrospective analysis. More than three stones were independent predictors of multiple sessions. ${ }^{24}$ In a retrospective cohort study comparing SOP-guided lithotripsy versus extracorporeal shock wave lithotripsy (ESWL), 
SOP-guided lithotripsy was associated with the requirement of less number of sessions and more complete clearance with similar adverse event rates. Stones $>1 \mathrm{~cm}$ was associated with failure of SOP-guided lithotripsy. ${ }^{25}$

\section{Step Out of Gut Wall}

\section{Evolution of Third-Space Endoscopy}

The scope of therapeutic endoscopy has increased manyfold with the introduction of natural orifice trans-luminal endoscopic surgery (NOTES). This has enabled the entry of flexible endoscopy into the second- and third-space (peritoneal cavity and submucosal space respectively). One of the major concerns with third space endoscopy was secure closure of the mucosal defect. Sumiyama et al have shown the safety of submucosal endoscopy with mucosal flap safety valve (SEMF) in which entry into the peritoneal cavity was safely closed with mucosal flap. ${ }^{26}$ Using the SEMF technique, Pasricha et al first performed endoscopic myotomy in an animal model in 2007. ${ }^{27}$ Subsequently, Inoue performed the first human case of peroral endoscopic myotomy (POEM) in 2008. ${ }^{28}$ The first case of submucosal tunneling and endoscopic resection (STER) for the submucosal tumor was also performed by Inoue in $2012 .^{29}$ Now, third-space endoscopy with SEMF is used in various GI disorders such as achalasia (POEM), sub-epithelial tumor (STER/peroral endoscopic tunneling: POET), refractory gastroparesis (gastric or G POEM), Zenker's diverticulum (Z-POEM), and esophageal stricture (POETRE-peroral endoscopic tunneling for restoration of the esophagus) ${ }^{26}$ Among these, POEM is the most popular technique of third-space endoscopy with vast experience worldwide. Gastroesophageal reflux disease (GERD) is the Achilles' heel of POEM procedure as a treatment of achalasia. New novel modalities such as POEM with endoscopic fundoplication have been introduced to mitigate this issue which was first reported by Inoue et al. ${ }^{30}$

\section{Peroral Endoscopic Myotomy}

Peroral endoscopic myotomy (POEM) is the most extensively studied third-space endoscopic procedure. The steps are submucosal injection, mucosal incision, submucosal tunneling, myotomy, and mucosal incision closure (-Fig. 4). Studies have shown excellent short and midterm results of POEM for achalasia but long-term results are scarce. ${ }^{26}$ Also, $94 \%$ clinical success rate at 1 year has been reported in a prospective study of 200 achalasia patients undergoing POEM. ${ }^{31}$ Subsequently the mid-term follow-up data ( 3 years) of 408 patients showed the highest clinical success at 3 years for type II achalasia (93.5\%) followed by type I (87.5\%) and type III achalasia (75\%). ${ }^{32}$ Similar efficacy and safety of POEM for prior treatment failure cases compared with treatment-naive patients have been shown in an analysis of more than 500 patients. $^{33}$ Various technical issues such as anterior versus posterior myotomy and short $(3 \mathrm{~cm})$ versus long myotomy $(\geq 6 \mathrm{~cm})$ have also been addressed by studies from India in randomized controlled trials. Anterior and posterior POEM had similar treatment efficacy where mucosectomies were more common in anterior POEM, whereas GERD was more common in posterior myotomy due to disruption of sling fibers. ${ }^{34}$ Short myotomy was shown to have similar success rates, adverse events, and GERD in type I and II achalasia with significantly shorter operating times. ${ }^{35}$ Type III achalasia requires long myotomy. Most of the adverse events are insufflation-related (e.g., pneumoperitoneum) that do not require active intervention and can be managed during the procedure without untoward consequences. ${ }^{31}$ Early recognition of bleeding points and hemostasis can be done by red dichromatic imaging (RDI). ${ }^{36}$ A novel multipurpose bipolar device can help obviate the need for a change of accessories in third space endoscopy as shown in a series of 10 cases which included seven cases of achalasia. ${ }^{37}$ POEM was also shown to be an effective and durable treatment for spastic esophageal motility disorders (Type III achalasia, Jackhammer esophagus, distal esophageal spasm- DES) with long term (5 years) success rate of $82.6 \%{ }^{38}$

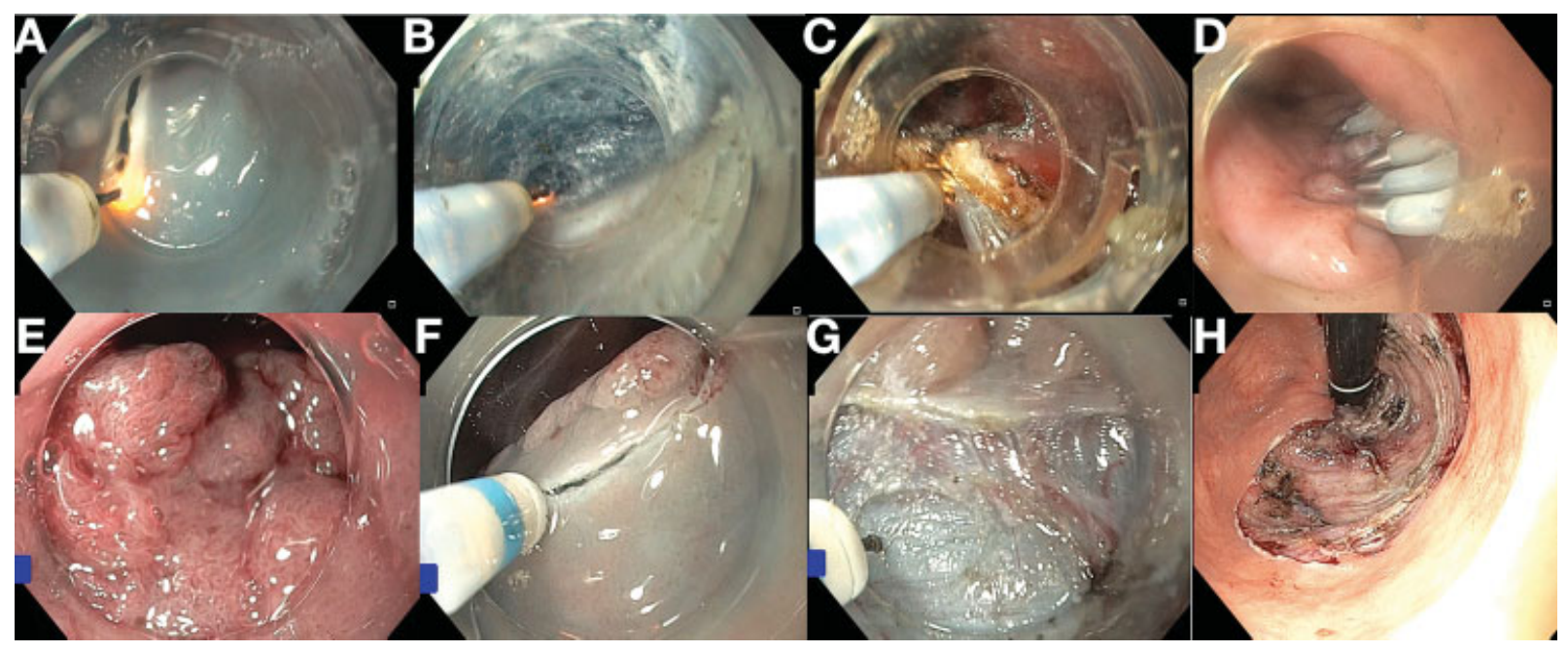

Fig. 4 Third-space endoscopy A-D: steps of POEM. (A) Mucosal incision. (B) Submucosal tunneling. (C) Myotomy. (D) Mucosal incision closure. $(\mathrm{E}-\mathrm{H})$ Endoscopic submucosal dissection (ESD). (E) Laterally spreading rectal tumor seen on a narrow band imaging near focus. (F) Mucosal incision. (G) Submucosal dissection. (H) Tumor bed after complete resection: turned out to be high-grade dysplasia. 
Most cases of post POEM GERD have been shown to be mild and proton pump inhibitor (PPI) responsive. None of the procedure-related factors can predict post POEM GERD. ${ }^{39}$ Identifying the twin penetrating vessels during myotomy can help prevent disruption of oblique fibers and thus GERD. ${ }^{40}$ Other novel technique to reduce reflux was simultaneous endoscopic fundoplication (POEM-F). ${ }^{41}$ Post POEM heartburn can occur due to acid fermentation, delayed esophageal clearance, stasis, and esophageal hypersensitivity other than true acidic reflux. ${ }^{42}$

\section{Third Space Endoscopy beyond POEM}

Large $(>3 \mathrm{~cm})$, submucosal tumors arising from muscularis propria can have malignant potential and can be resected endoscopically by submucosal tunneling and endoscopic resection (STER). The steps are similar to POEM except for tumor dissection and en bloc removal by snare instead of the myotomy. ${ }^{26}$ In a large series of 44 patients from India reported $99.7 \%$ technical success and $88.4 \%$ en bloc tumor removal with STER. Minor adverse events occurred in 16.9\% without any major adverse events. Leiomyoma and gastrointestinal stromal tumors (GIST) are the most common submucosal tumors resected. There was no difference in recurrence rate among those with piecemeal or en-bloc resection (-Fig. 4). ${ }^{43}$

Gastric POEM with pyloromyotomy can be helpful in refractory gastroparesis when pylorospam is the main pathophysiologic mechanism. It has comparable efficacy as laparoscopic pyloromyotomy with lower postoperative morbidity according to a prospective matched control study. ${ }^{44}$

$\mathrm{Z}$-POEM for Zenker's diverticulum can reduce the risk of perforation compared with conventional myotomy as the mucosa is preserved in D-POEM. ${ }^{26}$ Division of epiphrenic diverticulum (D-POEM) has been described by a single-center study from India in 13 patients with three quarters having associated motility disorder. It was effective in all cases with a single report of the major adverse event warranting surgery. ${ }^{45}$

\section{Conclusion}

The journey of the endoscopist in reaching out to the inaccessible areas in the GI tract has been remarkable. Substantial progress in GI endoscopy and technological evolution has led to improvement in techniques of deep enteroscopy, cholangiopancreatoscopy, and third-space endoscopy. Deep enteroscopy has now evolved from balloon-assisted enteroscopy to novel motorized spiral enteroscopy, which has made panenteroscopy a reality in the majority of cases. Cholangiopancreatoscopy has improved the evaluation of indeterminate biliary or pancreatic duct strictures with complete stone clearance in difficult cases. Third-space endoscopy is replacing surgical and other endoscopic management techniques in various GI disorders such as achalasia, refractory gastroparesis, subepithelial tumors, Zenker's, and epiphrenic diverticulum, and difficult esophageal strictures. The results of such newer modalities have so far been promising and reassuring. The future possibilities are never-ending as we push the limits of endoscopic innovation in reaching the inaccessible.

\section{Authors' Contributions}

Conceptualization: MR and PP; Literature review and writing original draft: PP and MR, Illustrations: IP and APS; Images: IP and APS; proofreading and critical review: PP, MR, DNR, IP, and APS, approving final manuscript: MR, PP, IP, APS, and DNR.

\section{Funding}

None.

Conflict of Interest

None declared.

\section{References}

1 Yamamoto H, Sekine Y, Sato Y, et al. Total enteroscopy with a nonsurgical steerable double-balloon method. Gastrointest Endosc 2001;53(02):216-220

2 Hartmann D, Eickhoff A, Tamm R, Riemann JF. Balloon-assisted enteroscopy using a single-balloon technique. Endoscopy 2007; 39(Suppl 1):E276

3 Domagk D, Mensink P, Aktas H, et al. Single- vs. double-balloon enteroscopy in small-bowel diagnostics: a randomized multicenter trial. Endoscopy 2011;43(06):472-476

4 Ramchandani M, Reddy DN, Gupta R, et al. Diagnostic yield and therapeutic impact of single-balloon enteroscopy: series of 106 cases. J Gastroenterol Hepatol 2009;24(10):1631-1638

5 Akerman PA, Agrawal D, Cantero D, Pangtay J. Spiral enteroscopy with the new DSB overtube: a novel technique for deep peroral small-bowel intubation. Endoscopy 2008;40(12):974-978

6 Baniya R, Upadhaya S, Subedi SC, et al. Balloon enteroscopy versus spiral enteroscopy for small-bowel disorders: a systematic review and meta-analysis. Gastrointest Endosc 2017;86(06):997-1005

7 Ramchandani M, Reddy DN, Gupta R, et al. Spiral enteroscopy: a preliminary experience in Asian population. J Gastroenterol Hepatol 2010;25(11):1754-1757

8 Ramchandani M, Rughwani H, Inavolu P, et al. Diagnostic yield and therapeutic impact of novel motorized spiral enteroscopy in small-bowel disorders: a single-center, real-world experience from a tertiary care hospital (with video). Gastrointest Endosc 2021;93(03):616-626

9 Beyna T, Arvanitakis M, Schneider M, et al. Motorised spiral enteroscopy: first prospective clinical feasibility study. Gut 2021;70(02):261-267

10 Beyna T, Arvanitakis M, Schneider M, et al. Total motorized spiral enteroscopy: first prospective clinical feasibility trial. Gastrointest Endosc 2021;93(06):1362-1370

11 Inavolu P, Singh AP, Kanakagiri H, Reddy DN, Ramchandani M. Motorized spiral enteroscope-assisted retrieval of video capsule in a patient with Crohn's disease. VideoGIE 2020;5(10): 488-491

12 Mukewar S, Carr-Locke D. Advances in endoscopic imaging of the biliary tree. Gastrointest Endosc Clin N Am 2019;29(02):187-204

13 Ramchandani M, Reddy DN, Gupta R, et al. Role of single-operator peroral cholangioscopy in the diagnosis of indeterminate biliary lesions: a single-center, prospective study. Gastrointest Endosc 2011;74(03):511-519

14 Ramchandani M, Nageshwar Reddy D, Lakhtakia S, Gupta R, Tandan M, Rao GV. Role of single-operator per-oral cholangioscopy and intraductal US in assessment of portal biliopathy (with videos). Gastrointest Endosc 2014;79(06):1015-1019

15 Shah RJ, Neuhaus H, Parsi M, Reddy DN, Pleskow DK. Randomized study of digital single-operator cholangioscope compared to fiberoptic single-operator cholangioscope in a novel cholangioscopy bench model. Endosc Int Open 2018;6(07):E851-E856. Doi: 10.1055/a-0584-6458 
16 Brewer Gutierrez OI, Godoy Brewer G, Zulli C, et al. Multicenter experience with digital single-operator cholangioscopy in pregnant patients. Endosc Int Open 2021;9(02):E116-E121. Doi: $10.1055 / \mathrm{a}-1320-0084$

17 Gerges C, Beyna T, Tang RSY, et al. Digital single-operator peroral cholangioscopy-guided biopsy sampling versus ERCP-guided brushing for indeterminate biliary strictures: a prospective, randomized, multicenter trial (with video). Gastrointest Endosc 2020;91(05):1105-1113

18 Ramchandani M, Reddy DN, Lakhtakia S, et al. Per oral cholangiopancreatoscopy in pancreatico biliary diseases-expert consensus statements. World J Gastroenterol 2015;21(15): 4722-4734

19 Almadi MA, Itoi T, Moon JH, et al; SpyGlass AMEA Registry Group. Using single-operator cholangioscopy for endoscopic evaluation of indeterminate biliary strictures: results from a large multinational registry. Endoscopy 2020;52(07):574-582

20 Maydeo AP, Rerknimitr R, Lau JY, et al; SpyGlass AMEA Registry Group. Cholangioscopy-guided lithotripsy for difficult bile duct stone clearance in a single session of ERCP: results from a large multinational registry demonstrate high success rates. Endoscopy 2019;51(10):922-929

21 Angsuwatcharakon P, Kulpatcharapong S, Moon JH, et al. Consensus guidelines on the role of cholangioscopy to diagnose indeterminate biliary stricture. HPB (Oxford) 2021

22 Ogura T, Takagi W, Onda S, Sano T, Higuchi K. Intraductal necrosectomy for pancreatic walled-off necrosis using novel single-operator pancreatoscope. Endoscopy 2016;48(S 01):E343

23 Arnelo U, Siiki A, Swahn F, et al. Single-operator pancreatoscopy is helpful in the evaluation of suspected intraductal papillary mucinous neoplasms (IPMN). Pancreatology 2014;14(06): 510-514

24 Brewer Gutierrez OI, Raijman I, Shah RJ, et al. Safety and efficacy of digital single-operator pancreatoscopy for obstructing pancreatic ductal stones. Endosc Int Open 2019;7(07):E896-E903. Doi: 10.1055/a-0889-7743

25 Bick BL, Patel F, Easler JJ, et al. A comparative study between single-operator pancreatoscopy with intraductal lithotripsy and extracorporeal shock wave lithotripsy for the management of large main pancreatic duct stones. Surg Endosc 2021

26 Nabi Z, Nageshwar Reddy D, Ramchandani M. Recent advances in third-space endoscopy. Gastroenterol Hepatol (N Y) 2018;14(04): 224-232

27 Pasricha PJ, Hawari R, Ahmed I, et al. Submucosal endoscopic esophageal myotomy: a novel experimental approach for the treatment of achalasia. Endoscopy 2007;39(09):761-764

28 Inoue $\mathrm{H}$, Minami $\mathrm{H}$, Kobayashi $\mathrm{Y}$, et al. Peroral endoscopic myotomy (POEM) for esophageal achalasia. Endoscopy 2010;42 (04):265-271

29 Inoue $\mathrm{H}$, Ikeda $\mathrm{H}$, Hosoya $\mathrm{T}$, et al. Submucosal endoscopic tumor resection for subepithelial tumors in the esophagus and cardia. Endoscopy 2012;44(03):225-230

30 Inoue $\mathrm{H}$, Ueno $\mathrm{A}$, Shimamura $\mathrm{Y}$, et al. Peroral endoscopic myotomy and fundoplication: a novel NOTES procedure. Endoscopy 2019; 51(02):161-164
31 Ramchandani M, Nageshwar Reddy D, Darisetty S, et al. Peroral endoscopic myotomy for achalasia cardia: treatment analysis and follow up of over 200 consecutive patients at a single center. Dig Endosc 2016;28(01):19-26

32 Nabi Z, Ramchandani M, Chavan R, et al. Per-oral endoscopic myotomy for achalasia cardia: outcomes in over 400 consecutive patients. Endosc Int Open 2017;5(05):E331-E339. Doi: 10.1055/ s-0043-105517

33 Nabi Z, Ramchandani M, Chavan R, et al. Peroral endoscopic myotomy in treatment-naïve achalasia patients versus prior treatment failure cases. Endoscopy 2018;50(04):358-370

34 Ramchandani M, Nabi Z, Reddy DN, et al. Outcomes of anterior myotomy versus posterior myotomy during POEM: a randomized pilot study. Endosc Int Open 2018;6(02):E190-E198

35 Nabi Z, Ramchandani M, Sayyed M, et al. Comparison of short versus long esophageal myotomy in cases with idiopathic achalasia: a randomized controlled trial. J Neurogastroenterol Motil 2021;27(01):63-70. Doi: 10.5056/jnm20022

36 Kv A, Ramchandani M, Inavolu P, Nabi Z, Reddy DN. Red dichromatic imaging in peroral endoscopic myotomy: a novel imageenhancing technique. VideoGIE 2021;6(05):203-206

37 Nabi Z, Chavan R, Ramchandani M, et al. Endoscopic submucosal dissection and tunneling procedures using a novel all-in-one bipolar device. Endosc Int Open 2020;8(10):E1302-E1307. Doi: 10.1055/a-1220-6562

38 Nabi Z, Chavan R, Ramchandani M, et al. Long-term outcomes of per-oral endoscopic myotomy in spastic esophageal motility disorders: a large, single-center study. J Clin Gastroenterol 2021;55(07):594-601. Doi: 10.1097/MCG.0000000000001395

39 Nabi Z, Ramchandani M, Kotla R, et al. Gastroesophageal reflux disease after peroral endoscopic myotomy is unpredictable, but responsive to proton pump inhibitor therapy: a large, singlecenter study. Endoscopy 2020;52(08):643-651. Doi: 10.1055/a1133-4354

40 Nabi Z, Ramchandani M, Kotla R, Chavan R, Darisetty S, Reddy DN. A simple modification in technique preserves oblique muscle fibers during peroral endoscopic myotomy. Endoscopy 2020;52 (01):E37-E38. Doi: 10.1055/a-0986-3112

41 Nabi Z, Ramchandani M, Darisetty S, Kotla R, Reddy DN. Peroral endoscopic myotomy with endoscopic fundoplication in a patient with idiopathic achalasia. Endoscopy 2020;52(01):74-75. Doi: 10.1055/a-0978-4627670

42 Ramchandani M, Pal P, Singla N, Reddy DN. Post-per-oral endoscopic myotomy heartburn: it is not always reflux: expert review. Dig Endosc 2021. Doi: 10.1111/den.14106

43 Nabi Z, Ramchandani M, Sayyed M, et al. Outcomes of submucosal tunneling endoscopic resection in upper gastrointestinal subepithelial tumors. Indian J Gastroenterol 2019;38(06):509-517. Doi: $10.1007 / \mathrm{s} 12664-019-00988-\mathrm{x}$

44 Landreneau JP, Strong AT, El-Hayek K, et al. Laparoscopic pyloroplasty versus endoscopic per-oral pyloromyotomy for the treatment of gastroparesis. Surg Endosc 2019;33(03):773-781

45 Nabi Z, Chavan R, Asif S, et al. Per-oral endoscopic myotomy with division of septum (D-POEM) in epiphrenic esophageal diverticula: outcomes at a median follow-up of two years. Dysphagia 2021 